\title{
Robust method for stator current reconstruction from DC link in a sensorless induction motor drive
}

\author{
S. B. Bodkhe ${ }^{1}$, M. V. Aware ${ }^{2}$ \\ ${ }^{1 *}$ Department of Electrical Engineering, G.H. Raisoni College of Engineering, Nagpur, INDIA \\ ${ }^{2}$ Department of Electrical Engineering, Visvesvaraya National Institute of Technology, Nagpur, INDIA \\ "Corresponding Author: e-mail: s_b_bodkhe@yahoo.co.in, Tel +91-9822718740,_Fax.+91-7104-232560
}

\begin{abstract}
The electronic inverters normally operate in a current controlled mode. Current controllers are prone to errors associated with nonlinearity and offsets in the current transducers. Their successful operation requires measurement of the instantaneous values of stator currents. Using the switching signals and dc link current, this paper presents a new algorithm for the reconstruction of stator currents of an inverter-fed, three-phase induction motor drive. Unlike the classical and improved methods available in literature, the proposed method is neither based on pulse width modulation pattern modification nor is a machine model based observer and therefore is independent of demerits of existing methods like higher switching loss and increased sensitivity to parameter variations. This makes it a robust solution. The proposed algorithm makes use of simple logic gates and if-else statements and as a result it generates stable three-phase current signals even during short periods of measurement. It also carries out auto-calibration of dc link current to remove the unwanted dc-offsets that are caused due to asymmetry in switching of semiconductor devices. The proposed algorithm is tested on a $2.2 \mathrm{~kW}$, current-regulated, field oriented control, induction motor drive by using MATLAB/Simulink software. The simulation results show good agreement between the reconstructed waveforms and actual waveforms under different operating conditions. Experimental result on a $2.2 \mathrm{~kW}$ induction motor drive, using a dSPACE 1104 controller board is presented to validate the proposed algorithm.
\end{abstract}

Keywords: Algorithm, current-reconstruction, current-sensor, dc-link, hysteresis modulation, three-phase induction motor.

\section{Introduction}

Fundamental to the successful operation of all ac drives is the ability to quickly and accurately control the motor torque, necessitating precise close-loop control of the motor phase currents. Three-phase voltage source inverters with closed-loop current regulator are widely used in many applications. Galvanically isolated current sensors are used in two or three of the inverter lines to provide the current feedback signals. Accurate measurement of these currents in the presence of high di/dt and dv/dt switching transients is difficult. It is also difficult to get current sensors with equal gain over a wide range of frequencies, voltages and currents. With more than one current sensor, the associated signal conditioning circuits increases the complexity, cost and size of the motor drive. Therefore the reduction in number of sensors is desirable (Jiang and Fahimi, 2010; Blaabjerg et al., 1997).

An alternative to direct measurement of the two phase currents is the reconstruction of phase currents by using the measured dc link current and the switching state information of the inverter. Since only one current sensor is used in the de link, intrinsically all the three phase currents are measured with the same gain and no dc-offset due to transducer can occur. A current sensor is usually present in the dc link of most drives that is employed for the over-current protection. Its output can be used for the dual purpose and thus no additional current sensors are required. Different types of current sensors are available in power electronics applications including the Hall Effect current transducer, current transformer and resistive shunts (Blaabjerg et al., 1997; Armstrong et al., 2006). Hall Effect sensors are widely used due to their good performance, relatively low cost and galvanically isolated principle of operation at relatively high frequency bandwidth.

The methods of reconstruction of phase currents, as reported in the referred literature may be classified in two major categories depending upon the way information from dc link is processed. The first category includes algorithms using pulse width 
modulation (PWM) pattern modification approach. For inverters controlled by space vector modulation (SVM), the reconstruction is simple when the dc link current is measured during active voltage vector instants (Blaabjerg et al., 1997). However when the active state does not satisfy the minimum timing requirement, the PWM sequence is modified at the expense of zero vector time period (Lee et al., 2000; Lee et al., 2001). The measurement voltage vectors are added along with conventional PWM pattern to cater to the problem of missing pulses (Kim and Jahns, 2006a; Kim and Jahns, 2006b). This approach improves the readability of phase currents in the dc link but due to added switching events, the inverter switching losses are higher. Also, in most of the SVM schemes with PWM pattern modification approach, the negative effects such as reduction of output r.m.s. voltage are present.

The second category deals in estimation of phase currents by employing the machine model based state observer. A predictive state observer which uses the load parameters is reported by Lee et al., (1999). A single-current space-phasor-observer with adaptation is proposed by Ying and Ertugrul, (2001). Saritha and Janakiraman, (2007) have used a Luenberger observer to estimate the three-phase currents. This technique is independent of load parameters. Three independent adaptive phase observers based on the use of induced electromotive force of the motor are suggested by Wolbank and Macheiner, (2002a); Wolbank and Macheiner, (2002b). The controller used by Vukosavic and Stankovic, (2001) is based on the calculation of active and instantaneous power out of de link quantities. Kolar et al., (2000) have reconstructed the line currents of boost type PWM rectifier out of de link samples based on hardware realization of three individual line-current-observers.

In this paper, the proposed phase current reconstruction technique is neither based upon PWM pattern modification nor it employs any machine model or load model based observer. It is based on the fact that, after two phase currents are picked up from the dc link during the measurable states, the third unmeasured phase current can be computed knowing that the sum of three phase currents is zero in a three-phase system without neutral connection. The problem of unwanted dc offsets due to asymmetry in switching is solved by an auto-calibrating dc link current sensing technique. The gaps created by missing pulses that could not be read in the dc link due to very short duration of switching states is filled by applying the if-hold logic. It is stated in literature that many current reconstruction schemes reported in the literature focus only on the phase current reconstruction without addressing the issues associated with current regulation using the reconstructed currents (Wolbank and Macheiner, 2004). In this paper, the reconstructed currents are used for current regulation by hysteresis modulation. The proposed procedure is discussed step-wise and is tested on a $2.2 \mathrm{~kW}$, field oriented controlled (FOC), induction motor (IM) drive. It is observed that the scheme works satisfactorily over a wide range of speed in both directions including low speeds close to zero. All these studies were carried out in MATLAB environment. Computer simulation and experimental implementation is carried out to verify the proposed algorithm.

\section{Sensorless induction motor drive based on dc link quantities}

So far, till beginning of this decade, the term sensorless referred to the absence of speed sensor only. During the last few years, speed-sensorless control of IM have been profusely investigated. The rotor speed is estimated instead being measured directly with a mechanical sensor. This leads to several advantages like lower cost, lower sensitivity to noise, increased reliability and robustness. A particular interest has been noted among researchers on applying the sensorless technique in FOC drives. Various estimator algorithms are available, the most commonly used being Model reference adaptive system and extended Kalman filter.

All speed estimators require at-least two current sensors and two voltage sensors on the stator side. But it is difficult to get current sensors with equal gain over a wide range of frequencies, voltages and currents. Failure of current sensors directly interrupts the system performance, and even causes disastrous consequences. Therefore the reduction in number of sensors is always desirable. An alternative to direct measurement of the stator currents and voltages is to reconstruct them by using the measured dc link quantities (current and voltage) and the switching state information of the inverter. Since only one current sensor is used in the dc link, intrinsically all the three phase currents are measured with the same gain and no dc-offset due to transducer can occur. A sensorless IM drive is presented in Figure 1. This paper concentrates only on the 'Reconstruction' block of this drive.

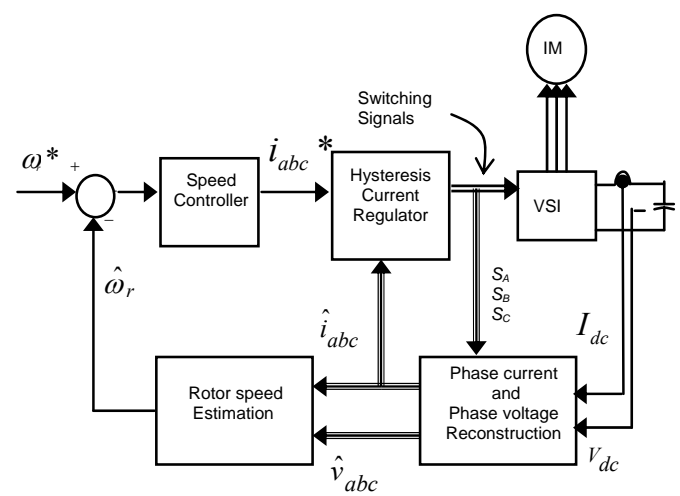

Figure 1. Speed sensorless induction motor drive based on dc link quantities 


\section{Dc link current}

The dc link current of a three-phase inverter appears to be a noise superimposed on steady value. Because of the snubber circuit and inductance associated with dc link wires, each time the inverter switching state changes, there exists a transient period over which the dc link current may differ substantially from the phase current. It is observed that there are both positive and negative spikes on the instantaneous dc link current waveform. The negative spikes are caused due to reverse recovery effect of freewheeling diodes during the dead-time period when both switches of the same leg of the inverter are off and the winding currents are flowing through freewheeling diodes (Chan et al., 1997). A dc current component may flow in the winding which is attributed to several factors like asymmetry in the switching of the semiconductor devices, imbalance in their turn-on and turn-off times, pulse-width imbalance in the PWM process or mismatch in the alignment of gate drive signals (Armstrong et al., 2006). As compared to sinusoidal and space vector PWM, such asymmetry and uncertainty of pulse-widths is more pronounced in hysteresis modulation (HM) that is normally used for current control (Rashid, 2005). Figure 2 shows the relationship of the PWM waveforms and dc link current for hysteresis modulation. Similar discussions for space vector PWM and sinusoidal PWM are available in (Blaabjerg et al., 1997) and (Bose, 2003) respectively.

In hysteresis modulation, the switching signals $S_{A}, S_{B}$ and $S_{C}$ undergo transition between high and low levels when the actual current signals $i_{a}, i_{b}$ and $i_{c}$ attain magnitude which lie outside the preset hysteresis band (HB). $i_{a}{ }^{*}, i_{b}{ }^{*}$ and $i_{c}{ }^{*}$ are the command current signals. The dc link current flows only when all the three switching signals are neither high nor low. It is equal to one of the motor phase currents or its opposite when each operating configuration of the inverter switches is considered. At different time intervals from $t_{1}$ to $t_{8}$ in Figure 1, the switching states and motor phase currents available in the dc link are presented in Table 1.

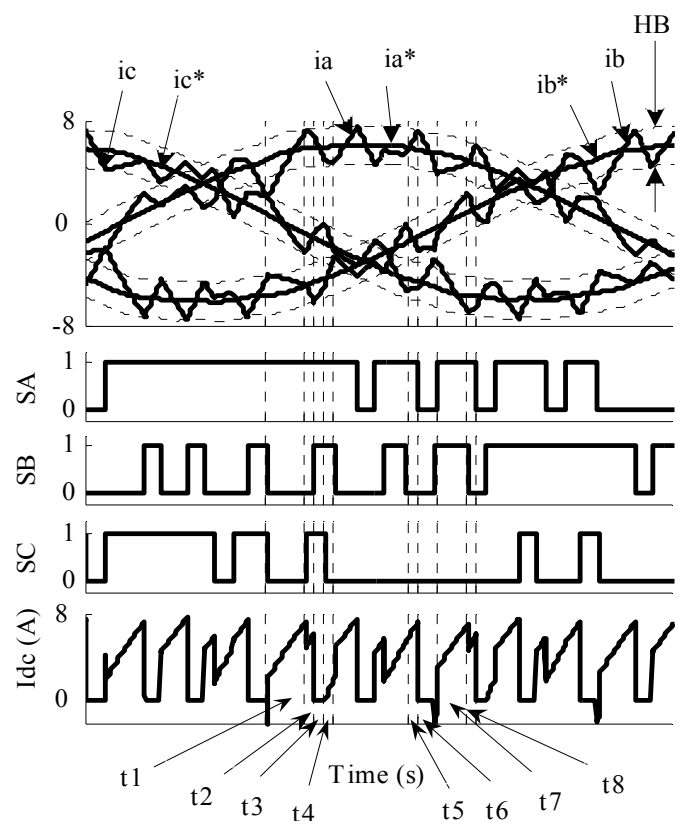

Figure 2. The relationship of PWM switching signals and dc link current in hysteresis modulation.

Table 1. Dc link current at different time intervals of Figure 2.

\begin{tabular}{ccc}
\hline $\begin{array}{c}\text { Time } \\
\text { interval }\end{array}$ & $\left(S_{A}, S_{B}, S_{C}\right)$ & $I_{d c}$ \\
\hline $\mathrm{t}_{1}$ & $(1,0,0)$ & $i_{a}$ \\
\hline $\mathrm{t}_{2}$ & $(1,0,1)$ & $i_{b}$ \\
\hline $\mathrm{t}_{3}$ & $(1,1,1)$ & 0 \\
\hline $\mathrm{t}_{4}$ & $(1,1,0)$ & $i_{c}$ \\
\hline $\mathrm{t}_{5}$ & $(1,0,0)$ & $i_{a}$ \\
\hline $\mathrm{t}_{6}$ & $(0,0,0)$ & 0 \\
\hline $\mathrm{t}_{7}$ & $(1,1,0)$ & $i_{c}$ \\
\hline $\mathrm{t}_{8}$ & $(1,0,0)$ & $i_{a}$ \\
\hline
\end{tabular}




\section{Proposed method of phase current reconstruction}

The proposed method for reconstruction of phase currents is an algorithm developed by using simple logic gates and if-else control flow statements. This algorithm needs the instantaneous value of dc link current and the inverter switching signals as inputs as is shown in Figure 3. Functionally, it can be divided into four parts or four steps. These are illustrated in the form of a flowchart in Figure 4. While carrying out these steps, it is ensured that the true value of current samples obtained from the dc link (with no dc-offset error) remains unaltered at all processing stages. In the first step, the measured dc link current is calibrated to make it free from unwanted dc offsets if any. The detailed description of each step is presented below.

\subsection{Step 1. Auto-calibration of dc link current:}

With modern PWM inverters, the speed and torque of IM can be reliably controlled even like a dc motor. The power switching devices are switched in such a way that both the magnitude and frequency of the motor voltage are varied to give whatever control option is required. However, due to asymmetry in the switching of semiconductor devices, unwanted dc current components flow in the inverter output which consequently also appears in the dc link. Such dc components can be attributed to several other factors also including imbalance in the turn-on and turn-off times, pulse-width imbalance in the PWM process, mismatch in alignment of gate drive signals, and offset due to current sensor. Analysis of such unwanted offset in the dc link for a one-phase H-bridge is presented by Armstrong, (2006).

The dc link current changes according to the different PWM switching states which also can be described as voltage vectors $\left(S_{A}, S_{B}, S_{C}\right)$ (Lee et al., 2000). These voltage vectors have eight different combinations i.e. $(0,0,0),(0,0,1),(0,1,0),(0,1,1),(1,0,0)$, $(1,0,1),(1,1,0)$ and $(1,1,1)$. The vectors $(0,0,0)$ and $(1,1,1)$ are called zero voltage vectors whereas the remaining six are termed as active voltage vectors. The most common topology of a three-phase, bridge type inverter with six semiconductor switches is shown in Figure 5. The switching signal $S_{A}$ is assigned a value ' 1 ' when the positive group switch of leg A is conducting else the assigned value is ' 0 '. Similarly are assigned the values to $S_{B}$ and $S_{C}$ for legs B and leg C respectively. During zero voltage vectors, the winding currents simply freewheel around the loops in the inverter bridge either through the semiconductor switches or through the freewheeling diodes and thus the current in dc link should be zero. But if the dc link current sensor output is monitored during these zero voltage vector periods then, due to the offset errors described above, a zero current measurement cannot be made. However, the true current in the dc link is known to be zero, therefore these periods are used to calibrate the current sensor and remove the offset.

The switching state of the bridge is deduced by monitoring gate drive signals. By using a mask with the help of logic gates, the zero voltage vectors are identified to record the freewheeling measurement through dc link current sensor. By employing a zeroorder hold, a continuous signal of the dc offset is obtained. The measured dc link current is calibrated by subtracting this dc offset from the measured dc link current during all switching states. The inverter output current is than reconstructed from the calibrated dc link current with no dc-offset error. Figure 6(a) \& (b) shows the measured and calibrated waveforms of dc link current.

\subsection{Step 2. Sampling of the calibrated dc link current:}

As discussed in section 1, the information related with three phase currents is present in the dc link. However all the three phase currents are not present on dc link simultaneously, only one can be obtained at any instant of time. The reconstruction of phase currents from the dc link current can be done only if two active vectors are present for at least enough time to be sampled. One active voltage vector reconstructs one phase current and the other voltage vector is used to reconstruct the second phase current. In other words, each switching state is composed of different active vectors and provides information on phase currents. The minimum time $T_{\min }$ required for reliable dc link current measurement is determined by the sum of the inverter dead time $t_{d}$, the diode reverse recovery time $t_{r r}$ and the sensor analog to digital acquisition time $t_{A D}$ (Kim and Jahns, 2006).

$$
T_{\text {min }}=t_{d}+t_{r r}+t_{A D}
$$

For a given phase, information is available in the dc link current when the positive group switch of a given leg in conjunction with either of the negative group switches in the other two legs are conducting or when the negative group switch of a given leg in conjunction with either of the positive group switches in the other two legs are conducting. It is analytically defined as follows. The calibrated dc link current is first sampled and then each sample is assigned to one of the three phase currents according to the specific inverter switches being gated at the instant of sampling. The relationship between active voltage vectors and the phase currents measured from the dc link is shown in Table 2. The partially reconstructed ac current of phase 'a' is shown in Figure 7.

$$
\begin{aligned}
& i_{a}=I_{d c}\left[S_{A}-\frac{S_{B}}{2}-\frac{S_{C}}{2}\right] \\
& i_{b}=I_{d c}\left[-\frac{S_{A}}{2}+S_{B}-\frac{S_{C}}{2}\right] \\
& i_{c}=I_{d c}\left[-\frac{S_{A}}{2}-\frac{S_{B}}{2}+S_{C}\right]
\end{aligned}
$$




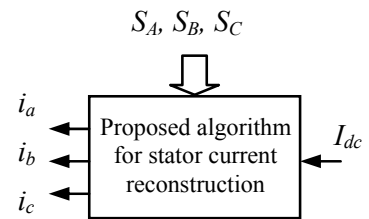

Figure 3. Input-output block diagram of the proposed current reconstruction method.

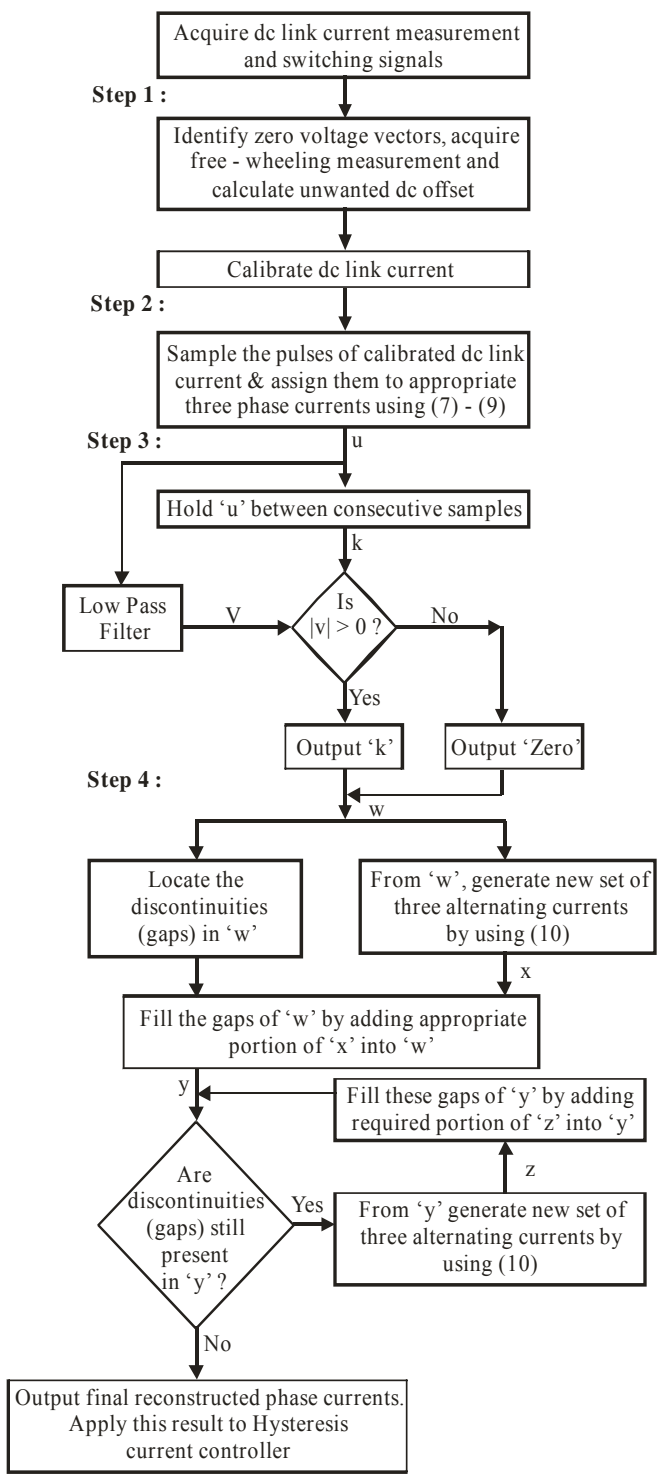

Figure 4. Proposed algorithm for phase current reconstruction

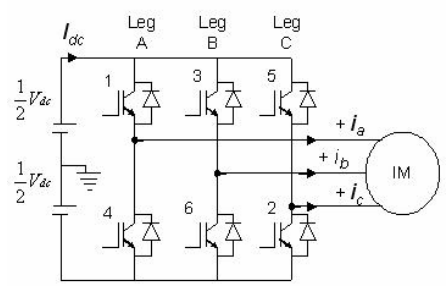

Figure 5. Voltage-source inverter fed induction motor drive 
Table 2. Dc link current \& voltage vectors

\begin{tabular}{ccccccc}
\hline $\begin{array}{c}\text { VoltageVector } \\
S_{A}, S_{B}, S_{C}\end{array}$ & $0,0,1$ & $0,1,0$ & $0,1,1$ & $1,0,0$ & $1,0,1$ & $1,1,0$ \\
\hline$I_{d c}(A)$ & $+i_{c}$ & $+i_{b}$ & $-i_{a}$ & $+i_{a}$ & $-i_{b}$ & $-i_{c}$ \\
\hline
\end{tabular}

\subsection{Step 3. If- hold stage}

The output of step 2 is in the form of discontinuous, non-uniform and interleaved short-duration pulses. To reconstruct continuous waveforms from this sampled data, a zero-order-hold ( $\mathrm{ZOH}$ ) or first-order-hold (FOH) could be used. Both, $\mathrm{ZOH}$ and FOH can convert sampled signals to continuous-time signals. The ZOH generates a continuous output by holding the input sample constant over one sample period while the FOH uses linear interpolation between the input samples to turn them into a continuous signal. However, both $\mathrm{ZOH}$ and $\mathrm{FOH}$ operate at specified sampling intervals. From Figure 7, it is observed that, the sampled data pulses neither have equal width nor are always equidistant from each other. Therefore, the use of $\mathrm{ZOH}$ or $\mathrm{FOH}$ which operates at fixed sampling intervals cannot give a continuous waveform of the shape that the actual phase currents possess.

In the proposed method, the if- hold logic is used to obtain a continuous output from the sampled input data. This logic holds the magnitude of a sample pulse having non-zero value, till the next non-zero sample arrives, thereafter it holds the magnitude of next sample and so on. This procedure is separately performed for the positive and negative half cycles of each phase current. The limitation of this method is that it introduces an unwanted dc offset in the region between the adjacent positive half cycles in one case and in between the adjacent negative half cycles of the another case. This is shown in Figures 8(a) \& (b). As a solution, a low pass filter (LPF) is used in parallel to decide which portion of the output given by the if-hold logic is acceptable. The time-constant for LPF is selected by trial and error. The combination of positive and negative sides is output of step 3 as is presented in Figure 9.

\subsection{Step 4. Gap filling}

The output of step 3 is formed by curve-fitting using the output of step 2. When the active state does not satisfy the minimum timing requirement as given by Eq. (1), the actual phase current pulses are not visible on the dc link measurement. Also, during the zero voltage vectors or during dead-time periods (Chan at el., 1997), the winding currents circulate in the inverter bridge and are not available in the dc link. Such un-measurable periods result in gaps and make the reconstructed waveform discontinuous. Therefore the next task is to fill such gaps without disturbing the already constructed portion. It is known that, in a three-phase star connected circuit without neutral path, the phasor sum of the three phase currents is zero. This fact can be utilized to fill the unwanted gaps after identifying their locations. Therefore from the three discontinuous outputs of step 3 i.e., $i_{a}, i_{b}$ and $i_{c}$ (Figure 8.), one new set of three waveforms $i_{a}^{\prime}, i_{b}^{\prime}$ and $i_{c}^{\prime}$ is constructed by using Eq. (5). Depending upon the location and width of gaps in the output of step 3, portions from $i_{a}^{\prime}, i_{b}^{\prime}$ and $i_{c}^{\prime}$ are cut and used as fillers to fill these gaps. When the dc link current samples are un-measurable, the gaps in reconstructed waveform are wide. These gaps can be filled by repeating step 4 until continuous waveforms are obtained. Figure 10 shows the final reconstructed phase currents obtained after implementing step 4, two times.

$$
i_{a}+i_{b}+i_{c}=0
$$

\section{The FOC induction motor drive with current regulation}

The current-regulated, FOC, inverter topology which has been used to test the proposed phase current reconstruction method is shown in Figure 11. It consists of a PWM voltage source inverter, a phase currents reconstruction block and a FOC block. The speed control loop uses a proportional-integral (P-I) controller to produce the quadrature-axis current command $i_{q e}{ }^{*}$ which controls the motor torque. The direct-axis current command $i_{d e} *$ is directly generated from the reference rotor flux $\psi_{r}{ }^{*}$. This eliminates an additional P-I controller and reduces the computational burden. These q-d commands expressed in synchronous frame are transformed to the three phase current commands $i_{a b c}{ }^{*}$ and are then compared with the reconstructed three-phase currents to generate the switching signals. For this purpose, hysteresis modulation method is adopted. In the proposed scheme, the phase currents $i_{a b c}$ are reconstructed from the dc link current $I_{d c}$ while the rotor speed signal $\omega_{r}$ is obtained from a speed sensor. The algorithm for the implementation of FOC is presented below (Bose, 2003; Vas, 1998). The rotor angular position is computed by Eq. (6) and Eq. (7).

The rotor flux $\psi_{r}$ is computed by Eq. (8).

$$
\begin{aligned}
\omega_{s l} & =\frac{R_{r} L_{m} I_{q}}{L_{r} \psi_{r}} \\
\theta & =\int\left(\omega_{s l}+\omega_{r}\right) \\
\psi_{r} & =\frac{L_{m} I_{d}}{\left(1+\frac{L_{r}}{R_{r}} s\right)}
\end{aligned}
$$


$I_{d}$ and $I_{q}$ are the reconstructed phase currents converted from $a-b-c$ frame to $d-q$ synchronous frame. The current command signal $i_{q e}{ }^{*}$ is the output of P-I controller which can be used to calculate the torque command $T_{e}{ }^{*}$. This is given by Eq. (9). The other command signal $i_{d e} *$ is obtained from reference rotor flux $\psi_{r} *$ as given by Eq. (10).

$$
\begin{gathered}
i_{q e^{*}}=\left(\frac{2}{3}\right)\left(\frac{2}{P}\right)\left(\frac{L_{r} T_{e}^{*}}{L_{m} \psi_{r}}\right) \\
i_{d e}{ }^{*}=\frac{\psi_{r}{ }^{*}}{L_{m}}
\end{gathered}
$$

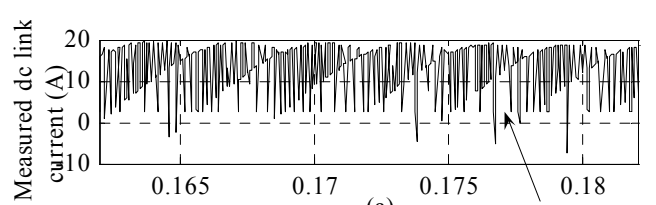

(a) unwanted dc offset

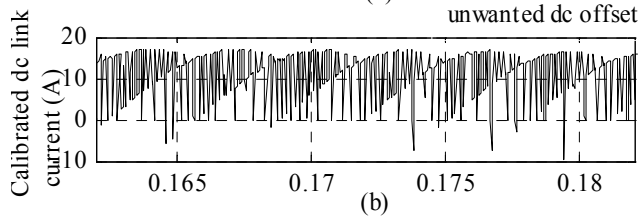

Figure 6. Dc link current (a) measured, (b) calibrated waveform.

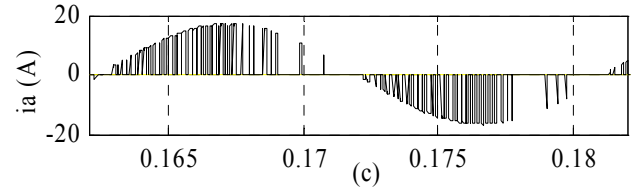

Figure 7. Output of step 2.

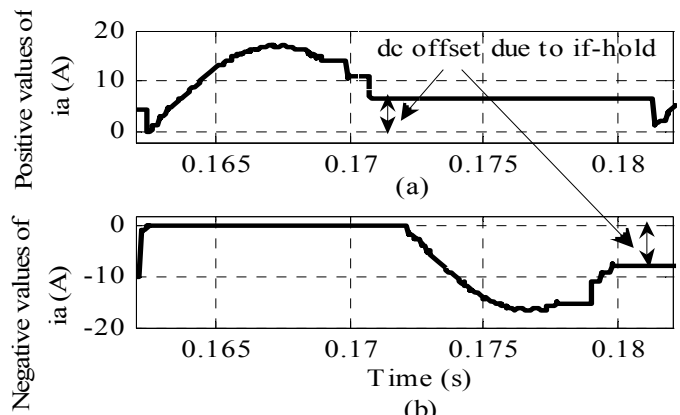

(b)

Figure 8. Output of If-hold logic.

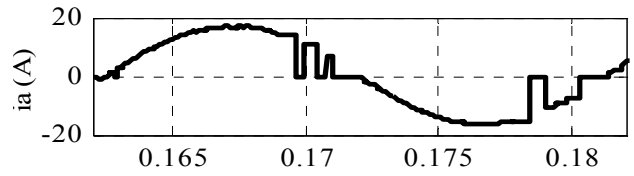

Figure 9. Output of step 3.

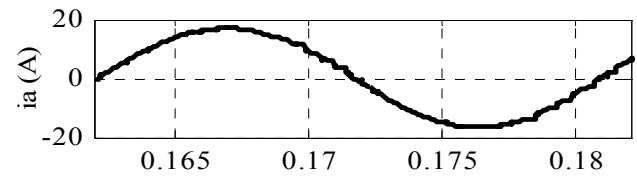

Figure 10. Output of step 4. 


\section{Simulation Studies}

In order to predict the performance of the proposed reconstruction algorithm and behavior of the drive during steady-state and transient conditions, detailed simulation study of the scheme shown in Figure 11 is carried out using MATLAB software. A Siemens make, three-phase, $415 \mathrm{~V}, 2.2 \mathrm{~kW}$, IM having star connected stator winding is taken for the tests. No-load and blocked rotor tests are performed to find out its parameters. The same parameters are verified through auto-tuning on a Eurotherm U.K. make, 860 series Ac drive. The parameters of motor are given in appendix. For close-loop speed control, indirect FOC method is used. The switching signals for inverter are generated by comparing the command phase currents that are generated by FOC with the reconstructed phase currents. Thus the inverter is operated in current controlled mode. This is implemented by adopting hysteresis modulation (HM) (Rashid, 2005). The reference rotor flux $\psi_{r} *$ is fixed at $0.96 \mathrm{wb}$ and the dc link voltage $V_{d c}$ is $600 \mathrm{~V}$.

The hysteresis band (HB) is fixed at $0.2 \mathrm{~A}$ which is $4.17 \%$ of the rated current. With $\mathrm{HM}$, the dc link current pulses depend upon the load, machine parameters and HB. Therefore the reconstructed currents shall be affected by HB. At high values of HB, less number of switching pulses are generated by the hysteresis controller while low values of HB results into more number of pulses spread over the entire cycle of Ac currents. By adjusting HB to appropriate value, the reconstruction of phase currents is possible over different operating conditions. Selection of HB can be done by trial and error. If the reconstructed currents are not getting updated over a longer time because of the narrow missing pulses, the HB can be reduced further. This was verified by selecting smaller value of HB (2\% of rated current) at very low speeds. For the reconstruction of phase currents, the dc link current is sampled with a sampling time of $2 \mathrm{e}^{-6} \mathrm{~s}$ and then all four steps as discussed in section 4 are carried out. The simulation was carried out for five different operating conditions as is presented ahead. A fixed-step, ode4 (Runge-Kutta) solver is used with step size of $2 \mathrm{e}^{-6} \mathrm{~s}$. To check the accuracy of reconstructed waveforms, the phase currents are obtained by two different methods. The first one is the proposed method and in the second one, dynamic model of IM is used (Vas, 1998). The simulation results of the first method are treated as reconstructed values while those of the latter method as actual values. The error in reconstruction is calculated as given by Eq. (11). Following tests are performed to evaluate the performance of proposed scheme.

$$
\text { Error }=\text { Actual value }- \text { Reconstruc ted value }
$$

\section{Test 1: Free acceleration characteristics}

The machine is allowed to accelerate from zero speed to rated speed at no-load. The steady-state was reached at $0.2 \mathrm{~s}$. The reconstructed phase currents and the error involved are shown in Figures 12 (a) \& (b). As a measure of drive performance, the instantaneous torque and the instantaneous rotor speed are presented in Figures 12(c). The dc link current is also shown in this figure.

\section{Test 2: Speed reversal}

A step change in speed reference from $+100 \%$ to $-100 \%$ is applied at $0.725 \mathrm{~s}$. The motor is on no-load condition. This step change is equivalent to $100 \%$ speed change. The reconstructed currents and the reconstruction error are shown in Figures 13 (a) \& (b). The phase sequence of reconstructed currents gets reversed to rotate the rotor in opposite direction. The response time for this operation is $325 \mathrm{~ms}$. This proves the accuracy of the proposed scheme even during $100 \%$ speed reversal.

\section{Test 3: Step change in load}

A step change in load torque from zero to rated value is applied at $1.6 \mathrm{~s}$. This is shown in Figures 14 (a)-(c). The electromagnetic torque increases to correct the speed error. Upon reaching steady-state, the torque becomes equal to the load torque. The rotor speed, after a small drop attains back its earlier value. The motor reaches steady state in $10 \mathrm{~ms}$. The magnitude of reconstructed currents increases from no-load to rated value of 1.0 p.u. which corresponds to $4.8 \mathrm{~A}$.

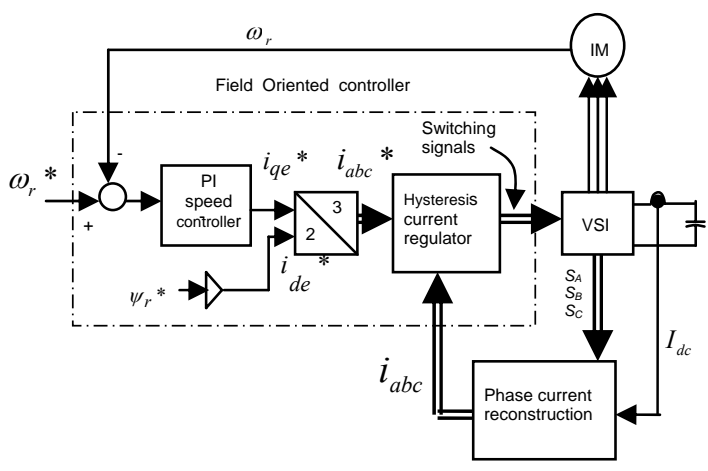

Figure 11. Block diagram of the FOC IM drive with current regulation. 
Test 4: Low speed operation

The responses of the drive at $40 \%, 10 \%, 1 \%$ and $-1 \%$ of rated speed are shown in Figure 15 where the rated speed of 1.0 per unit corresponds to $1425 \mathrm{rpm}$. The corresponding drop in the frequency of reconstructed currents is observed in Figure 15 (a). Thus the performance of proposed method is stable even at very low speed range.

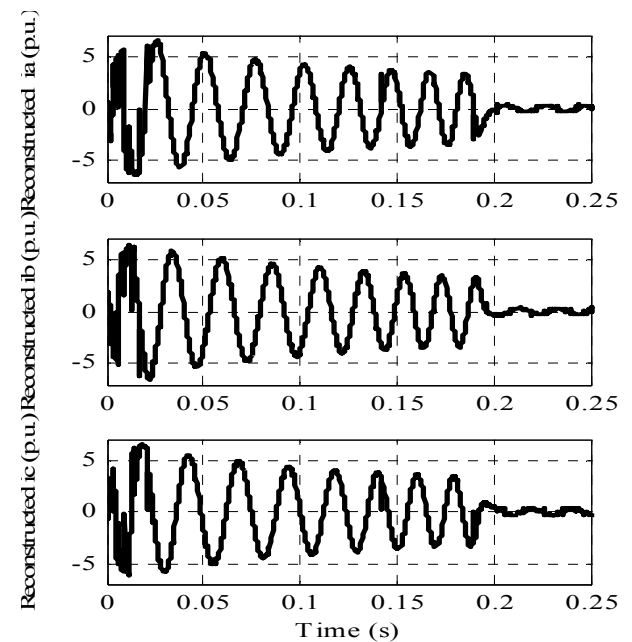

(a)

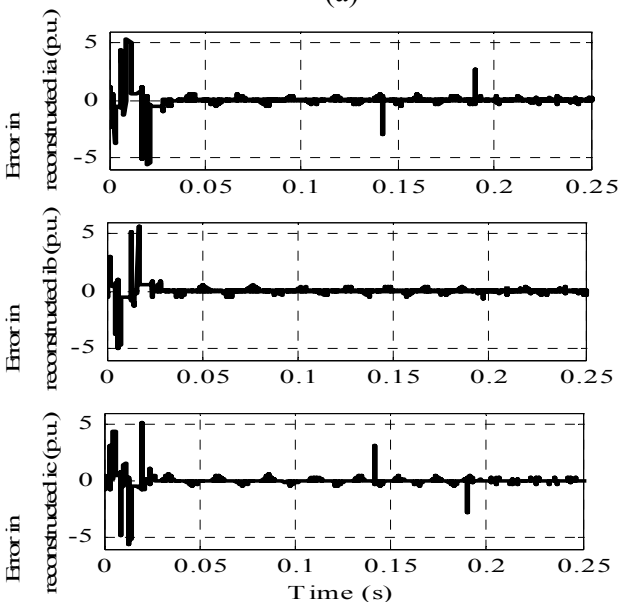

(b)
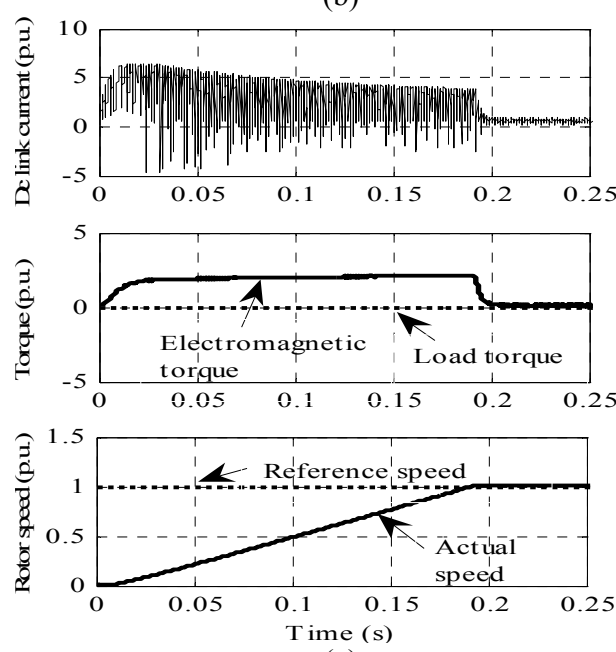

(c)

Figure 12. Simulation results for free acceleration

(a) reconstructed phase currents $i_{a}, i_{b}, i_{c}$ in (p.u.),

(b) error in reconstructed currents $i_{a}, i_{b}, i_{c}$ in (p.u.),

(c) dc link current, torque $\&$ rotor speed all in (p.u.).

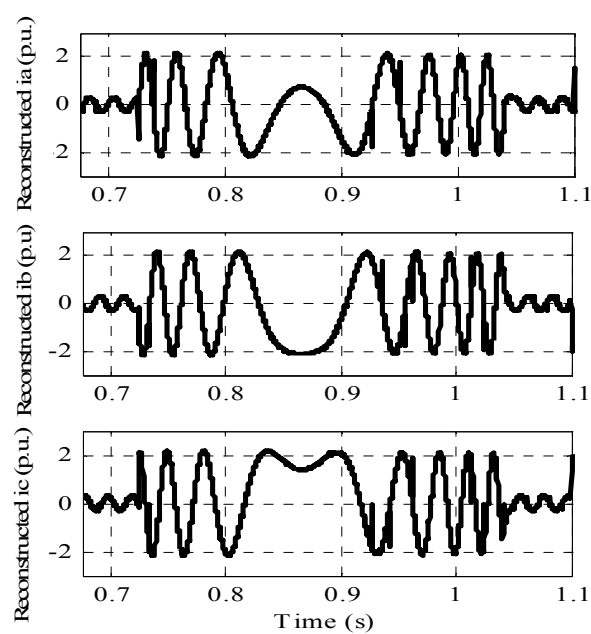

(a)
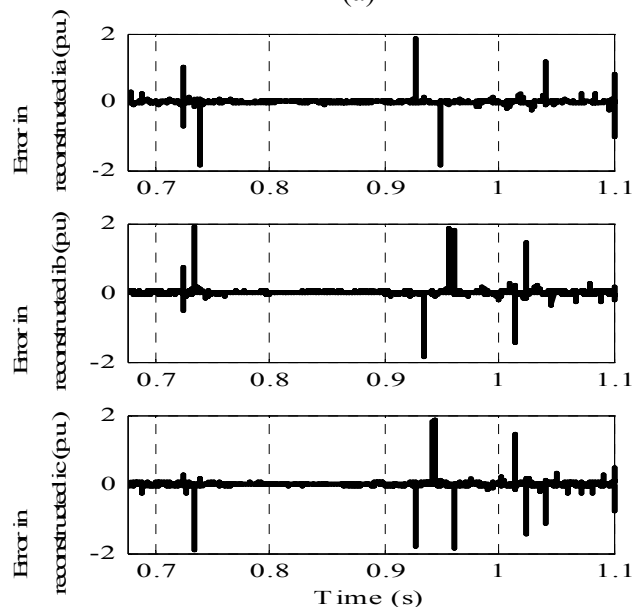

(b)
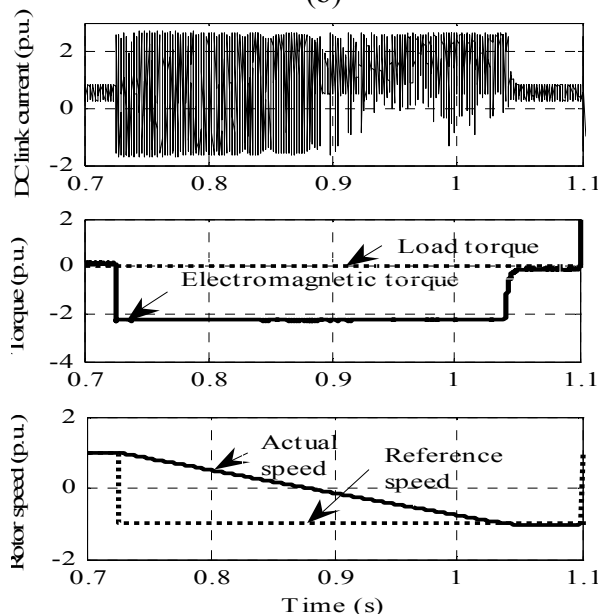

(c)

Figure 13. Simulation results for speed reversal.

(a) reconstructed phase currents $i_{a}, i_{b}, i_{c}$ in (p.u.),

(b) error in reconstructed currents $i_{a}, i_{b}, i_{c}$ in (p.u.),

(c) dc link current, torque $\&$ rotor speed all in (p.u.). 


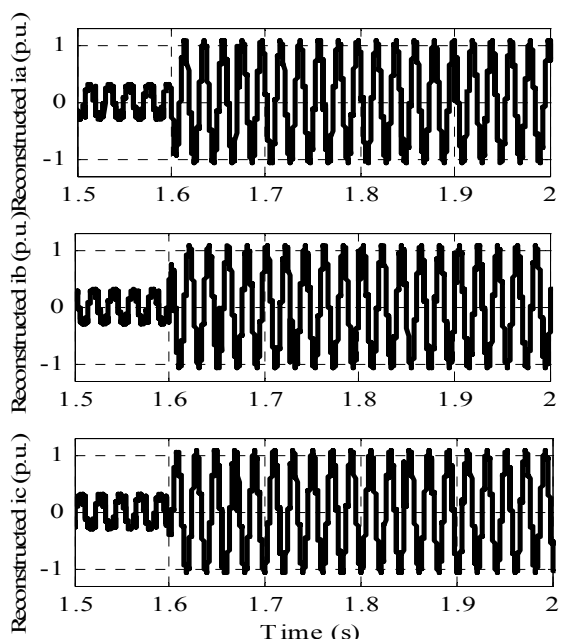

(a)
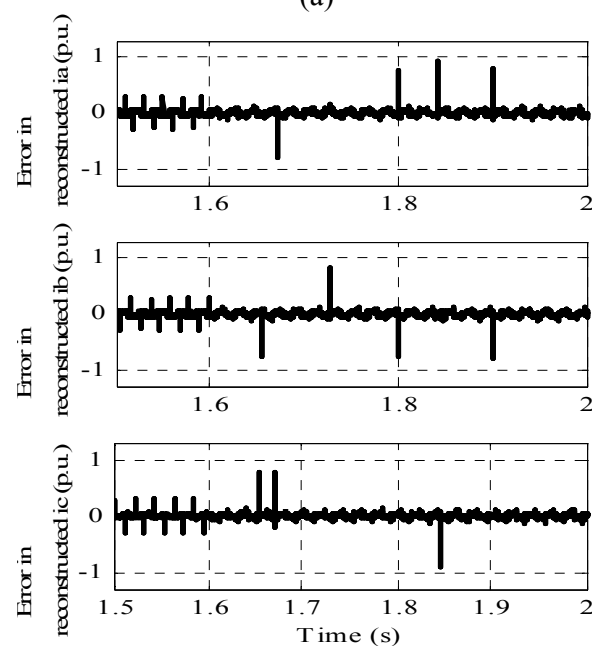

(b)
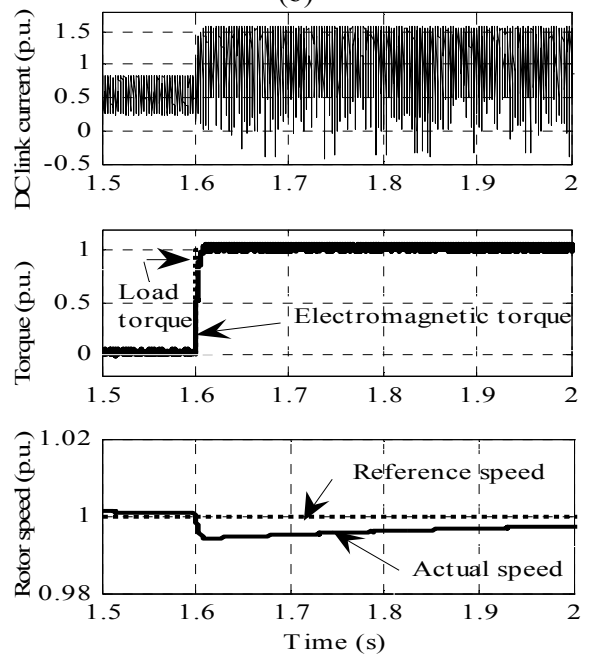

(c)

Figure 14. Simulation results for step change in load torque.

(a) reconstructed phase currents $i_{a}, i_{b}, i_{c}$ in (p.u.),

(b) error in reconstructed currents $i_{a}, i_{b}, i_{c}$ in (p.u.),

(c) dc link current, torque \& rotor speed all in (p.u.).
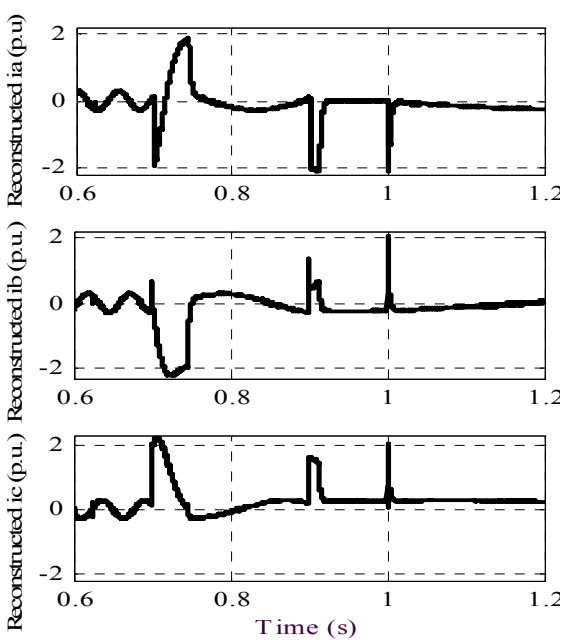

(a)
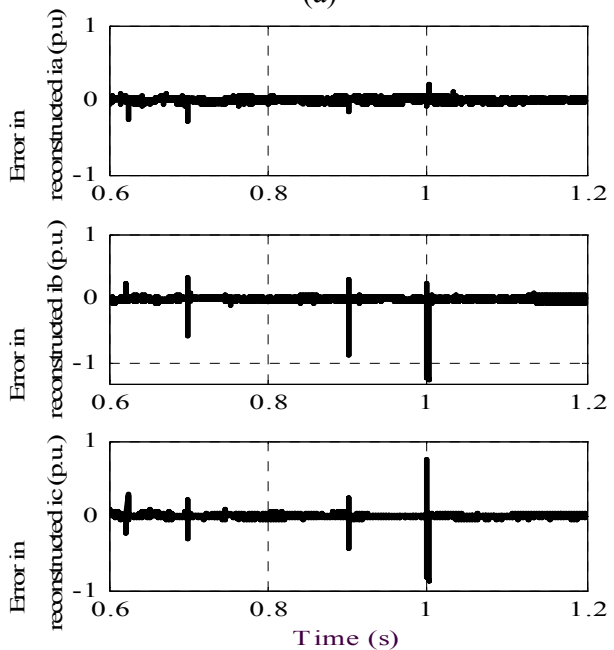

(b)
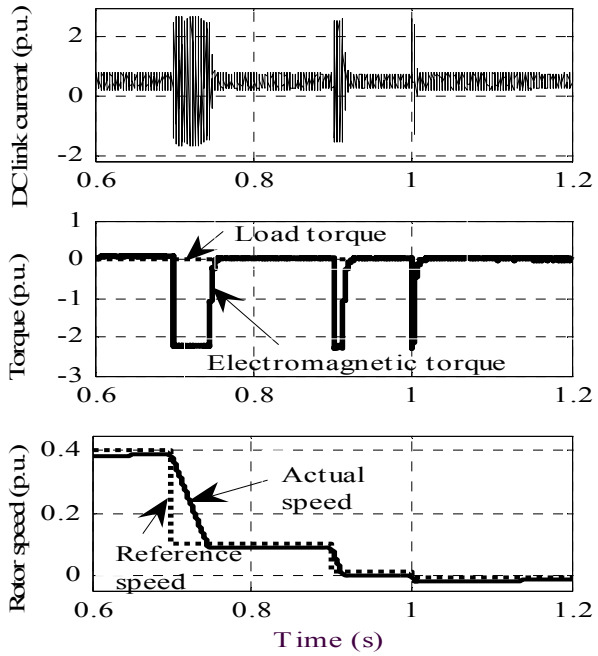

(c)

Figure 15. Simulation results for low speed operation.

(a) reconstructed phase currents $i_{a}, i_{b}, i_{c}$ in (p.u.),

(b) error in reconstructed currents $i_{a}, i_{b}, i_{c}$ in (p.u.),

(c) dc link current, torque \& rotor speed all in (p.u.). 
From above tests, it is clear that the proposed method of reconstruction of stator currents from the dc link current has very less error which is within $\pm 2 \%$ and it works accurately under different dynamic and steady-state conditions. The reconstructed currents can be reliably used for feedback in a current controlled PWM inverter fed IM drive without using any physical sensors to measure the actual currents.

\section{Experimentation}

Experimental verification of the proposed current reconstruction algorithm is done on a prototype consisting of a $2.2 \mathrm{~kW}$ induction motor driven by a three-phase insulated gate bipolar transistor (IGBT) based PWM inverter. The block diagram of the experimental setup is shown in Figure 16. The measurement system employs a Hall effect dc current transducer for the dc link current measurement, one signal conditioning circuit that include opto-couplers 6N137 for PWM signals and a dSPACE DS1104 controller board for implementation of the proposed algorithm.

The PWM inverter is built using an IPM- PM25RSB120. The DS1104 system is installed in the 32-bit PCI slot of a Pentium PC and has a connector panel for connections between the board and external devices. The dSPACE board has two DSPs in masterslave configuration. The master processor (a Power PC 603e core, 64-bit, floating point unit running at $250 \mathrm{MHz}$ ) is responsible for all major operations while the slave processor (a Texas Instruments TMS320F240, 16-bit, fixed point unit running at $20 \mathrm{MHz}$ ) is dedicated to I/O communications. This board was programmed with MATLAB/Simulink software. It gave full access to the programming variables and allowed them to be visualized and modified. The implementation of the proposed algorithm has been carried out using the fixed-step ode1 (Euler) solver. Results are obtained by means of user-friendly trace options of the controller board and a digital storage oscilloscope, saved on a standard PC for graphic post-processing. The reconstructed stator current of phase $A$ is presented in Figure 17.

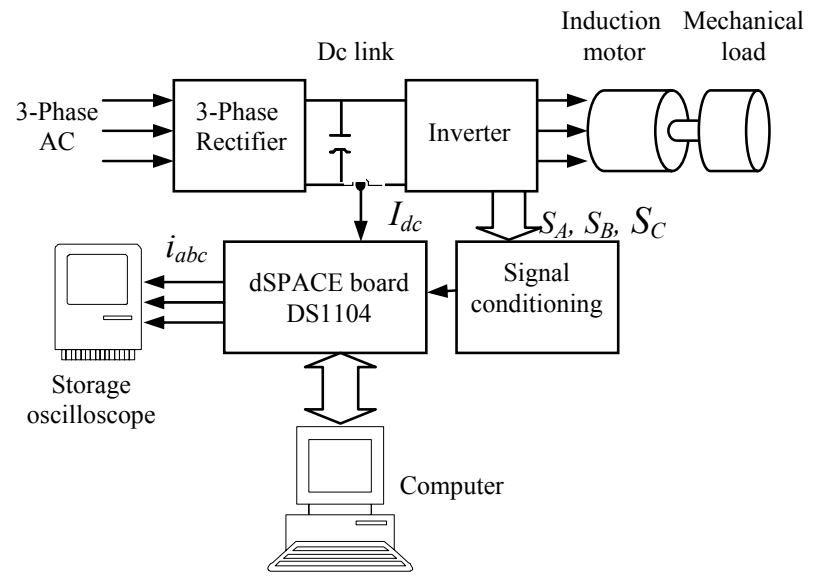

Figure 16. Block diagram of the experimental set-up

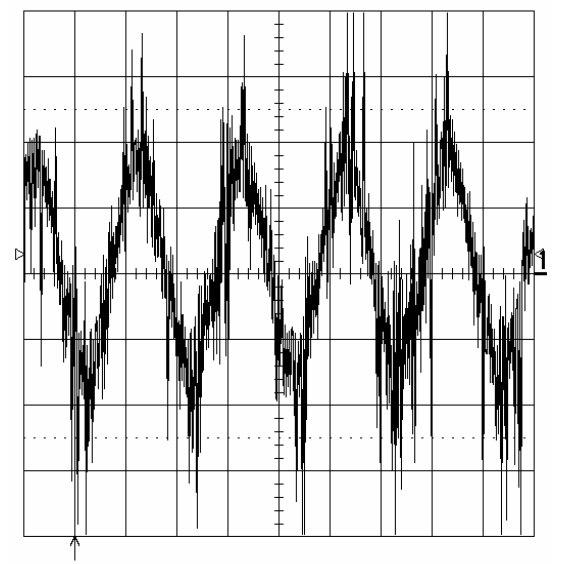

Figure 17. Experimental result showing reconstructed stator current of phase- $A, 10 \mathrm{~ms} / \mathrm{div}, 20 \mathrm{mV} / \mathrm{div}$. 


\section{Conclusion}

A new method for stator current reconstruction from the dc link current for a current regulated, inverter fed induction motor drive is proposed in this paper. The basic principle of the proposed method is discussed step-wise. This technique eliminates the limitations associated with the use of two or three physical current sensors on the stator side. The dc link current signal can be obtained from the current sensor that is already available in the dc link of any drive for protection purpose. Thus additional current sensor is not needed. This makes the scheme cost effective. Unlike existing methods of current reconstruction available in literature, the proposed method is independent of machine parameters and therefore is robust against any variation in their magnitudes. From the simulation results, it is observed that, the difference between reconstructed stator currents and the actual stator currents with regards to phase displacement, attenuation and amplification is negligibly small under different operating conditions. The error is within $\pm 2 \%$. The proposed method gives accurate dynamic and steady-state results over a wide speed range including very low speeds close to zero. It works in both directions of rotor speed. The experimental verification of proposed algorithm using dSPACE 1104 board shows that it can be easily implemented on any digital signal processor.

\section{References}

Armstrong M., Atkinson D. J., Johnson C. M. and Abeyasekera T. D., 2006. Auto-calibrating dc link current sensing technique for transformerless, grid connected, H-bridge inverter systems, IEEE Transactions on Power Electronics, Vol. 2, No. 5, pp. 13851393.

Blaabjerg F., Pederson J. K., Jaeger U. and Thoegersen P., 1997. Single current sensor technique in the dc link of three- phase

PWM-VS inverters: A review and a novel solution, IEEE Transactions on Industry Applications, Vol. 33, No. 5, pp. 1241-1253.

Bose B. K., 2003. Modern power electronics and ac drives, Pearson Education Singapore Pte. Ltd.

Chan C. C., Chau K. T. and Li Y., 1997. A novel dead-time vector approach to analysis of de link current in PWM inverter drives, Proc. Applied Power Electron. Annu. Conf. and Expo., 1, Atlanta, 1997, pp. 338-344.

Jiang W., Fahimi B., 2010. Current reconstruction techniques for survivable three-phase PWM converters, IEEE Trans. on P. E., Vol. 25, No. 1, pp. 188-192.

Kim H. and Jahns T. M., 2006a. Current control for ac motor drives using a single dc-link current sensor and measurement voltage vectors, IEEE Trans. on Ind. Appl., Vol. 42, No. 6, pp. 1539-1547.

Kim H. and Jahns T. M., 2006b. Phase current reconstruction for ac motor drives using a dc link single current sensor and measurement voltage vectors, IEEE Trans. on P. E., Vol. 21, No. 5, pp. 1413-1419.

Kolar, J. W., Stoegerer F., Miniboeck J. and Ertl H., 2000. A new concept for reconstruction of the input phase-currents of a threephase/switch/level $\{\mathrm{PWM}(\mathrm{Vienna})\}$ rectifier based on neutral point current measurement, Proc. IEEE Power Electronics Specialists Conf., Vol. 1, , pp. 139-146.

Lee W. C., Hyun D. S. and Lee T. K. 1999. Single sensor current control of a three-phase voltage source PWM converter using predictive state observer, Proc. 25 th Annu. Conf. IEEE Ind. Electro. Soc., 2, San Jose, CA, pp. 691-796.

Lee W. C., Hyun D. S. and Lee T. K., 2000. A novel control method for three-phase PWM rectifiers using a single current sensor, IEEE Trans. on P. E., Vol. 15, No. 5, pp. 861-870.

Lee W. C., Hyun D. S. and Lee T. K., 2001. Comparison of single-sensor current control in the dc link for three-phase voltage source PWM converters, IEEE Trans. Ind. Electron., Vol. 48, No. 3, pp. 491-505.

Rashid M. H., 2005. Power electronics-circuits, devices, and application, Prentice-Hall New Delhi, India,

Saritha B. and Janakiraman P. A., 2007. An observer for three-phase current estimation using nonuniform current samples, IEEE

Power Electron. Lett., Vol. 22, No. 2, , pp. 686-692.

Vas P., 1998. Sensorless Vector and Direct Torque Control, Oxford University Press Inc. NY,.

Vukosavic S. and Stankovic A. M., 2001. Sensorless induction-motor drive with a single de link current sensor and instantaneous active and reactive power feedback, IEEE Trans. Ind. Electron., Vol. 48, pp. 195-204.

Wolbank T. M. and Macheiner P. E., 2002a. An improved observer based current controller for inverter fed ac machine with single dc link current measurement, Proc. IEEE PESC, pp. 1003-1008.

Wolbank T. M. and Macheiner P. E., 2002b. Scheme to reconstruct phase current information of inverter fed AC drives, Electron. Lett., Vol. 38, No. 5, pp. 204-205.

Wolbank T. M. and Macheiner P. E., 2004. Current-controller with single dc link current measurement for inverter-fed ac machines based on an improved observer-structure, IEEE Trans. on P. E., Vol. 19, No. 6, pp. 1562-1567.

Ying L. and Ertugrul N., 2001. A novel estimation of phase-currents from dc link for permanent magnet ac motors, Proc. IEEE Electrical Electronic Technology Conf., pp. 606-612. 


\title{
Appendix
}

\author{
Machine Parameters
}

$R_{s}=11.1 \Omega ; R_{r}^{\prime}=2.2605 \Omega: L_{s}=0.7329 \mathrm{H} ;$

$L_{r}^{\prime}=0.7329 \mathrm{H} ; L_{m}=0.71469 \mathrm{H} ; P=4$.

\section{Biographical notes}

S. B. Bodkhe completed his graduation in electrical engineering from Walchand College of Engineering, Sangli (M.S.), India in 1990 and the M.Tech degree from Visvesvaraya Regional College of Engineering, Nagpur (M.S.), India in 1996. After his graduation, he worked with V.I.P. Industries Ltd., Nagpur and then joined Ramdeobaba K. N. College of Engineering, Nagpur as Lecturer in 1992. In 2000, he joined the Electrical Engineering Department of G. H. Raisoni College of Engineering, Nagpur as Assistant Professor. Presently he is pursuing his Ph.D. at Visvesvaraya National Institute of Technology, Nagpur. Mr. Bodkhe received the Best Teacher Award from Raisoni Group of Institutions in 2007. He is an author of two books on 'Electrical Engineering' published by M/s. S. Chand \& Co., Delhi and M/s PPH Pvt. Ltd. Nagpur. He has presented/ published many research papers in national/international journals and conferences. His areas of interest are electric machines, power electronics and drives.

Dr. M. V. Aware received the B.E. degree in electrical engineering from the Government College of Engineering, Amravati (M.S.), India, in 1980, the M.Tech. degree from the Indian Institute of Technology, Bombay, India, in 1982, and the Ph.D. from Visvesvaraya Regional College of Engineering, Nagpur, India, in 2002. After his post graduation, he worked as a Design Officer with Crompton Greaves Ltd., Nasik, India. In 1991, he joined the Electrical Engineering Department, Visvesvaraya Regional College of Engineering, as a Lecturer. Since 1994, he has been with the Power System Research Laboratory, Visvesvaraya Regional College of Engineering as a Scientist "C". From 2001 to 2003, he was Research Associate with the Electrical Engineering Department, Hong Kong Polytechnic University, Kowloon, Hong Kong. Presently, he is working as a Professor in Electrical Engineering Department at Visvesvaraya National Institute of Technology, NAGPUR (INDIA). He is member of Bureau of Energy Efficiency (BEE) and also recognized Energy Auditor.

Received September 2010

Accepted November 2010

Final acceptance in revised form December 2010 